\title{
A CASE REPORT: POSTERIOR PITUITARY EVALUATED AS MICROADENOMA IN THE MAGNETIC RESONANCE IMAGING
}

\section{Introduction}

- The posterior pituitary lobe stores the neurosecretory granules and appears as hyperintense on T1 weighted sagittal magnetic resonance images .

- $\quad$ The pituitary adenoma appears as hypointense on T1 weighted magnetic resonance images.

- We report a case whose posterior pituitary lobe mimicking microadenoma.

\section{Case report}

\section{Medical history}

- A 20-year-old woman evaluated in Gynecology for oligomenorrhae..

- Magnetic resonance imaging of pituitary showed a nodular lesion on the left parasagittal region measured $3 \mathrm{~mm}$ in diameter.

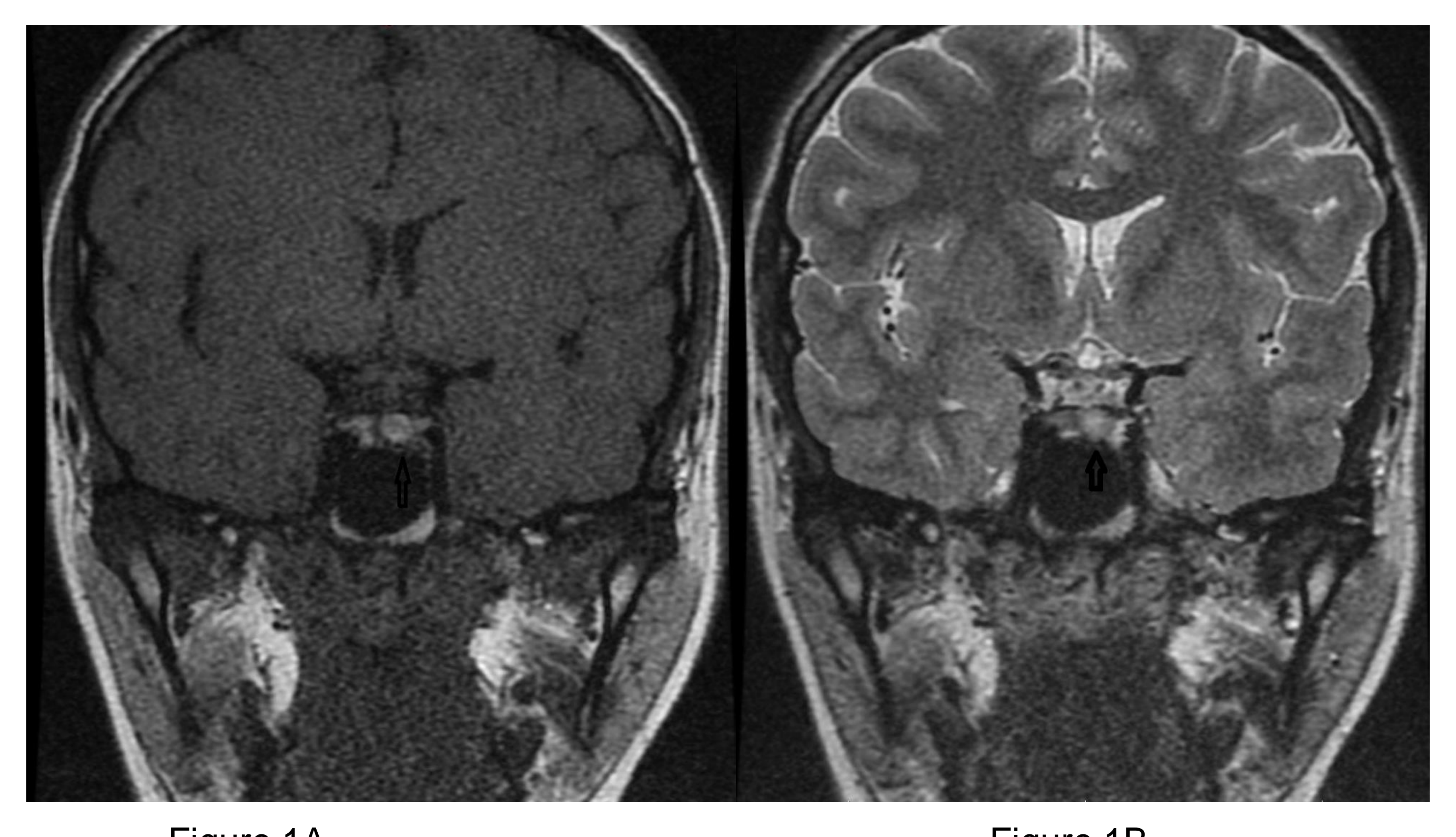

Figure $1 \mathrm{~A}$

Figure 1B

- $\quad$ The lesion was hypointense on T1 weighted (Figure1A) and little hyperintense on T2 weighted (Figure 1B) images which could not be distinguished from artifactial lesion.

- $\quad$ She was refered to Endorinology.

\section{Laboratory}

$\begin{array}{lll}\text { FSH } & 4.59 & \mathrm{mlU} / \mathrm{mL} \\ \text { LH } & 6.95 & \mathrm{mlU} / \mathrm{mL} \\ \text { Prolactin } & 27 & \mathrm{ng} / \mathrm{mL} \\ \text { FT4 } & 1.12 & \mathrm{ng} / \mathrm{dL} \\ \text { TSH } & 1.98 & \mu \mathrm{lU} / \mathrm{mL} \\ \text { Cortisol } & 30.99 & \mu \mathrm{g} / \mathrm{dL} \\ \text { ACTH } & 33.5 & \mathrm{pg} / \mathrm{mL} \\ \text { 1 mg Dex. sup. } & 0.887 & \mu \mathrm{gg} / \mathrm{dL} \\ \text { Somatomedin-C } & 271 & \mathrm{ng} / \mathrm{mL} \\ \text { GH } & 1.23 & \mathrm{mlU} / \mathrm{L}\end{array}$

\section{Radiology}

- $\quad$ After three months magnetic resonance of pituitary showed a nodular lesion on the left parasagittal posterior region measured $6 \mathrm{~mm}$ in diameter.

The lesion was more hyperintense on $\mathrm{T} 1$ weighted images than adenoma and was not taking contrast agent like a cyst.

- The appearance of the lesion could be interfered with fat tissue, sphenoid bone or partial volume artifact.

- $\quad$ The fat-suppressed images were taken; there was no change of intensity on dynamic series and no contour lobulation.

- When axial fat-suppressed images were examined the lesion was identified as the posterior pituitary lobe (Figure 2)

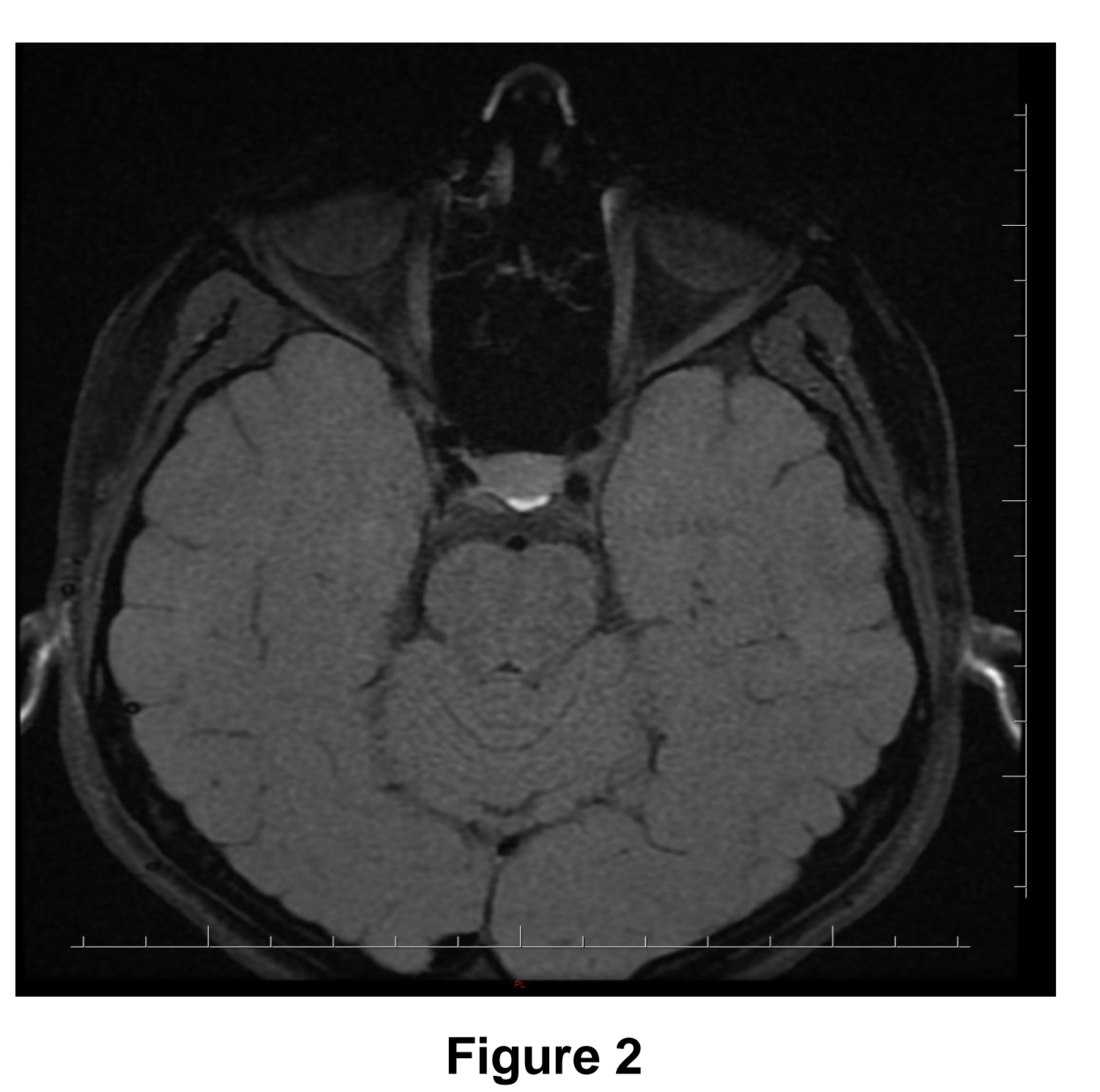

\section{Conclusion}

- We report a case of posterior pituitary lobe which was a little asymmetrically thickened and localized on the left parasagittal region.

- $\quad$ This localization caused pseudonodular appearance when surrounded with anterior pituitary lobe on coronal images.

- $\quad$ The posterior pituitary lobe may appear as a hyperintense nodular lesion on T1 weighted images which can be identified with fat-suppressed axial images.

- This is different from the ectopic posterior pituitary which mostly located within the hypothalamus.

- $\quad$ Some anatomical variations may affect the diagnosis of pituitary lesions like suspicious microadenomas.

- $\quad$ The patients may have unnecessary evaluation for a long period. 